\title{
Nonpharmacological Treatment for Supporting Social Participation of Adults with Depression
}

\author{
Supaluck Phadsri $\mathbb{D}^{1,2}$ Rieko Shioji ${ }^{1},{ }^{1}$ Atsuko Tanimura ${ }^{1},{ }^{1}$ Jeerawit Jaknissai $\left(\mathbb{D},{ }^{3}\right.$ \\ Sopida Apichai ${ }_{(D)}{ }^{2}$ and Tippawan Sookruay ${ }^{4}{ }^{4}$
}

${ }^{1}$ Department of Occupational Therapy, Tokyo Metropolitan University, Tokyo 116-8551, Japan

${ }^{2}$ Department of Occupational Therapy, Chiang Mai University, Chiang Mai 50200, Thailand

${ }^{3}$ Occupational Therapy Unit, Thanyarak Khon Kaen Hospital, Khon Kaen 40000, Thailand

${ }^{4}$ Chiang Mai University Library, Chiang Mai University, Chiang Mai 50200, Thailand

Correspondence should be addressed to Rieko Shioji; rshioji@tmu.ac.jp

Received 10 October 2020; Revised 16 March 2021; Accepted 9 April 2021; Published 29 April 2021

Academic Editor: Claudia Hilton

Copyright (c) 2021 Supaluck Phadsri et al. This is an open access article distributed under the Creative Commons Attribution License, which permits unrestricted use, distribution, and reproduction in any medium, provided the original work is properly cited.

\begin{abstract}
Background. Social withdrawal is predominantly seen among adults with depression. However, a dearth of reviews exists that explore nonpharmacological treatments, especially occupational therapy (OT) interventions and their effect in promoting social participation. The aim of this research was to review what intervention programs are conducted to support the social participation of adults with depression and their effectiveness. Method. A systematic review was performed wherein relevant articles were searched in PubMed, CINAHL, Wiley Online Library, PsycINFO, and OTseeker databases and AJOT, BJOT, SJOT, and OTMH journals. Only English articles published from January 2010 to December 2018, which tackled intervention for adults aged 20-60 years with depression, were considered. Ten out of 918 studies met the screening criteria. Result. Among the ten studies, the effective intervention programs were categorized as either occupation-based intervention (OBI) or cognitive behavioral therapy-based intervention (CBT-BI). These programs sought the following outcomes: behavioral change in social participation $(n=4)$, reduction of depression or depressive symptoms $(n=13)$, life satisfaction $(n=4)$, and quality of life (QoL) $(n=1)$. Studies showed moderate $(n=3)$ to strong $(n=7)$ level of certainty, whereas they also revealed high to unclear $(n=3)$ and low $(n=7)$ risk of bias. Conclusion. Both OBI such as animal-assisted therapy and CBT-BI such as behavioral change program and health education have a strong level of certainty and low risk of bias in promoting social participation by supporting positive behavioral change and reducing depressive symptoms. Furthermore, the sport and exercise program of OBI was popular in encouraging participation and engagement with other people. Other programs were suggested for combined interventions to support social participation, life satisfaction, and QoL.
\end{abstract}

\section{Introduction}

Depression is a global concern and is predicted to become the leading, serious, and chronic noncommunicative disease by 2030 [1]. Depression is frequently revealed by an individual's poor social experience and impaired social functioning [2]. Furthermore, depression may produce long-term behavioral change by increasing social avoidance $[3,4]$, which has an impact on one's occupation, especially social participation [5]. As people with depression are overwhelmed with negative thoughts and have a lesser drive to participate in social activities, they are at a high risk of experiencing a relapse of symptoms, resulting in diminished self-love, life satisfaction, and quality of life (QoL) [6]. The importance of occupational performance and social participation is supported and covered by activity and participation in the World Health Organization's International Classification of Functioning, Disability, and Health (ICF) [7].

Social participation is defined in the occupational therapy profession as "the interweaving of occupations to support desired engagement in community and family activities as well as those involving peers and friends, ... and that support 
social interdependence" [5]. As social participation plays an essential role in recovering from depression, occupational therapy practitioners should deliver occupation-focused interventions that "support the development of relationship and companionship with peers, friends, partners, and pets, which are very important in social participation" [8].

The literature review revealed that nonpharmacological treatment is the preferred treatment option by the majority of people with depression $[4,9]$. The negative perception of pharmacological treatment [4] among this group is mainly due to the unpleasant side effects they experienced, such as drowsiness, weight gain, fatigue, constipation, and sexual dysfunction $[10,11]$, which often led to inadequate work capacity and loss of social functioning [6]. Furthermore, receiving pharmacological treatment may demand special supervision from other people, which could be a burden for the family and community [12]. Thus, even if they agreed to use antidepressants for retaining functional ability [11], the promotion of social participation with nonpharmacological treatment is still required in order to assist in reducing depressive symptoms $[13,14]$ and enrich social interaction, social identity, participation, and sense of belonging [15]. These benefits, in turn, provide opportunities to improve life satisfaction and QoL $[6,8]$.

To manage depression and improve mental and social health, individuals with depression need to work themselves and cooperate with other people in the community and society. Therefore, supportive social participation and rehabilitation processes of adults with depression are typically motivated by the recovery and active management of their illness in terms of personal and social well-being [8]. While several reviews about social participation have been published, these reviews looked into older adults and focused on social participation as a subconstruct of leisure $[16,17]$ or considered insufficient studies with a low level of evidence [18]. In realizing the importance of social participation in providing treatments for individuals with depression, healthcare professionals, including occupational therapy practitioners, need to update their knowledge on current research evidence and effective practical guidance to improve intervention programs for promoting social participation among adults with depression.

The objective of this research was to review intervention programs that support the social participation of adults with depression and their effectiveness. This systematic review only included research studies of nonpharmacological treatment that resulted in behavioral and emotional changes in social participation for the primary focus and also included other effective factors resulting from the intervention programs such as life satisfaction and QoL as relevant to achieve the objective.

\section{Methods}

This systematic review followed the guideline of the Preferred Reporting Items for Systematic Reviews and MetaAnalyses (PRISMA) [19] and focused on nonpharmacological treatment to improve social participation of adults with depression. Research articles involving hospital and commu- nity rehabilitation services were included. The researchers considered the studies with Sackett's evidence-based medicine levels I, II, and II [20, 21] and the Oxford Centre for Evidence-Based Medicine (OCEBM) [22] (Table 1). Although randomized control trial (RCT) studies have been accepted as the gold standard of study design to examine the effects of an intervention [23], this study considered setting an eligibility criteria for participants that might influence the response of an intervention program; for example, age, diagnosis, and severity of physical movement. This review followed the definition of social participation provided by the "Occupational Therapy Practice Framework: Domain and Process 4th Edition" [5], which means covering desired participation in community and family activities or involving peers and friends or any subset of activities that relate to social issues, including social participation through remote technologies. This definition was used in selecting the key terms for the search strategy. Thus, the screening process included articles within the occupational therapy, physical therapy, psychotherapy, medicine/psychiatry, and nursing disciplines. This systematic review was registered on PROSPERO 2019 (CRD42019135525).

2.1. Search Strategy. The Patient/Problem, Intervention, Comparison, Outcome (PICO) method $[19,24]$ was used to formulate research questions. Participants were persons with depression, the intervention was nonpharmacological treatment, the comparison was not applicable, and the outcome was social participation (behavioral and emotional change). The researchers searched and recorded the number of studies in the searching step. Literature search was conducted across five electronic databases: PubMed, CINAHL, Wiley Online Library, OTSeeker, and PsycINFO. To further ensure that studies were not left out, the researchers carried out additional hand searches by reviewing the table of contents on the sites of four occupational therapy journals: American Journal of Occupational Therapy (AJOT), British Journal of Occupational Therapy (BJOT), Scandinavian Journal of Occupational Therapy (SJOT), and Occupational Therapy in Mental Health (OTMH).

2.2. Inclusion and Exclusion Criteria. The inclusion criteria in the initial stage of screening were peer-reviewed scientific articles on adults with depression aged 20 to 60 years old, published in English between January 2010 and December 2018. Searching articles and hand searches were completed in one month. This review included only journal articles and excluded non-peer-reviewed research literature, presentations, conference proceedings, and dissertations. The researchers only considered intervention programs directly provided to persons with depression. The research team considered studies concerning persons with depression and physical comorbidity for inclusion as these individuals face many barriers to social participation. All documents and information were logged and validated by the researchers (SP, RS, AT, JJ, SA, and TS).

The exclusion criteria were as follows: (1) study with other groups of participants unrelated to the purpose of this research, which consisted of (1.1) animal or drug study, 
TABLE 1: The level of evidence.

\begin{tabular}{lc}
\hline Level & Type of evidence \\
\hline Level I & Systematic reviews, meta-analyses, randomized controlled trials \\
Level II & Two groups, nonrandomized studies (e.g., cohort, case-control) \\
Level III & One group, nonrandomized (e.g., before and after, pretest and posttests) \\
Level IV & Descriptive studies that include analysis of outcomes (single-subject design, case series) \\
Level V & Case reports and expert opinion that include narrative literature reviews and consensus statements \\
\hline
\end{tabular}

Adapted from Sackett's evidence-based medicine [20, 21] and the Oxford Centre for Evidence-Based Medicine (OCEBM) [22].

(1.2) development of assessment tool, (1.3) family, caregiver, stakeholder, and other groups (e.g., occupational therapy practitioner or students), (1.4) nonspecific participants (e.g., severe mental illness or psychosis), and (1.5) individuals aged $<20$ or $>60$ years; (2) different research types of evidence, such as (2.1) qualitative study and (2.2) studies not categorized as evidence-based medicine levels I-III; (3) social participation not being the central aspect in the research; and (4) not an intervention program for persons with depression.

2.3. Screening, Eligibility, and Data Extraction. Studies were searched and identified independently through databases by SP and TS, using sets of key terms, and additional hand searches were conducted by SP and JJ. Retrieved studies underwent title and abstract screening, performed independently by SP and JJ. Studies were dismissed at this stage if they did not match the screening criteria, as were the studies with social participation defined remarkably differently from this. In case of any doubt, SA, who has higher qualification and research experience, made the final decision after thorough deliberation and critical thinking. Reference lists of the studies included were also reviewed to ensure their relevance. Next, SP retrieved the full text of the remaining articles, arranged, categorized, and grouped the studies into a spreadsheet before assessing the strength of evidence and risk of bias. The other researchers double-checked each stage.

2.4. Synthesis and Quality of Assessing Risk of Bias. The researchers provided a narrative synthesis of the findings. It was structured around the types of intervention programs, characteristics of the target population, and types of outcomes. The guidelines from the U.S. Preventive Services Task Force [24] was used to critique the strength of the evidence (Table 2). This study examined the risk of bias by using the guideline from the Cochrane Handbook for Systematic Reviews of Interventions [25] for nonsystematic reviews and the Assessment of Multiple Systematic Reviews (AMSTAR) for systematic reviews, respectively, with the latter having good development [26], reliability, and construct validity and feasibility [27].

\section{Results}

3.1. Search Results. The search found 1,135 studies in the screening process. Among these, ten studies (Berget et al. 2011 [28], Graven et al. 2011 [29], Ammerman et al. 2013 [30], Nagy et al. 2017 [31], Chen et al. 2019 [32], Strøm et al. 2019 [33], Kern et al. 2019 [34], Rogers et al. 2014
[35], Cruwys et al. 2014 [36], Croezen et al. 2015 [37]) were assessed as eligible and were included in the analysis and synthesis (Figure 1). Each study and its details after analysis have been shown in Table 3.

3.2. Study Characteristics. In the analysis and synthesis of results, seven of the ten studies (Berget et al. 2011 [28], Graven et al. 2011 [29], Ammerman et al. 2013 [30], Nagy et al. 2017 [31], Chen et al. 2019 [32], Strøm et al. 2019 [33], Kern et al. 2019 [34]) were at level I, while the other three studies (Rogers et al. 2014 [35], Cruwys et al. 2014 [36], Croezen et al. 2015 [37]) were at level III of research levels of evidence. In ten studies, two studies (Berget et al. 2011 [28], Rogers et al. 2014 [35]) were obtained from occupational therapy literature, while the other eight studies were derived from nursing, psychology, and medicine and public health disciplines. The studies from occupational therapy literature included participants diagnosed with not only depression but also other psychiatric problems or symptoms such as posttraumatic stress disorder (PTSD) (Rogers et al. 2014 [35]), schizophrenia, and personality and behavioral disorder (Berget et al. 2011 [28]). Four of the 10 studies categorized the participants into depressive symptoms with comorbidities, such as stroke (Graven et al. 2011 [29]), head and neck cancer (HNC) (Chen et al. 2019 [32]), spine fusion (Strøm et al. 2019 [33]), and obesity (Kern et al. 2019 [34]), while one study cultivated in depressed mothers (Ammerman et al. 2013 [30]).

3.3. Intervention Programs. Two major categories of intervention were found with 13 specific programs (Table 4). First, occupational-based intervention (OBI) had six programs. Second, cognitive behavioral therapy-based intervention (CBT-BI) had seven programs.

3.4. Effectiveness of the Intervention Programs. These programs sought the following four outcomes: behavioral change of social participation $(n=4)$, reducing depression or depressive symptoms $(n=13)$, life satisfaction $(n=4)$, and quality of life $(n=1)$.

3.4.1. Behavioral Change in Social Participation. The results of four programs showed positive behavioral changes in social participation. First, AAT (Berget et al. 2011 [28]) reflected well on subjective experience toward increased function, interaction, and satisfaction while working with and physically touching animals. Interpersonal communication was shown in increased extroversion and talkative expression, which were associated with self-esteem and 
TABLE 2: Strength of evidence (level of certainty).

Strength Description
Strong
(i) Two or more level I studies
(ii) The available evidence usually includes consistent results from well-designed, well-conducted studies. The findings are
strong, and they are unlikely to be strongly called into question by the results of future studies
(i) At least one level I high-quality study or multiple moderate-quality studies (level II, level III, etc.)
(ii) The available evidence is sufficient to determine the effects on health outcomes, but confidence in the estimate is constrained
by such factors as
Moderate (i) the number, size, or quality of individual studies
(ii) inconsistency of findings across individual studies
As more information (other research findings) becomes available, the magnitude or direction of the observed effect could change,
and this change may be large enough to alter the conclusion related to the usefulness of the intervention
(i) Small number of low-level studies, flaws in the studies, etc.
(ii) The available evidence is insufficient to assess effects on health and other outcomes of relevance to occupational therapy.
Evidence is insufficient because of the following:
(i) The limited number or size of studies
(ii) Important flaws in study design or methods
(iii) Inconsistency of findings across individual studies
(iv) Lack of information on important health outcomes
More information may allow estimation of effects on health and other outcomes of relevance to occupational therapy

Reference: the U.S. Preventive Services Task Force [24].

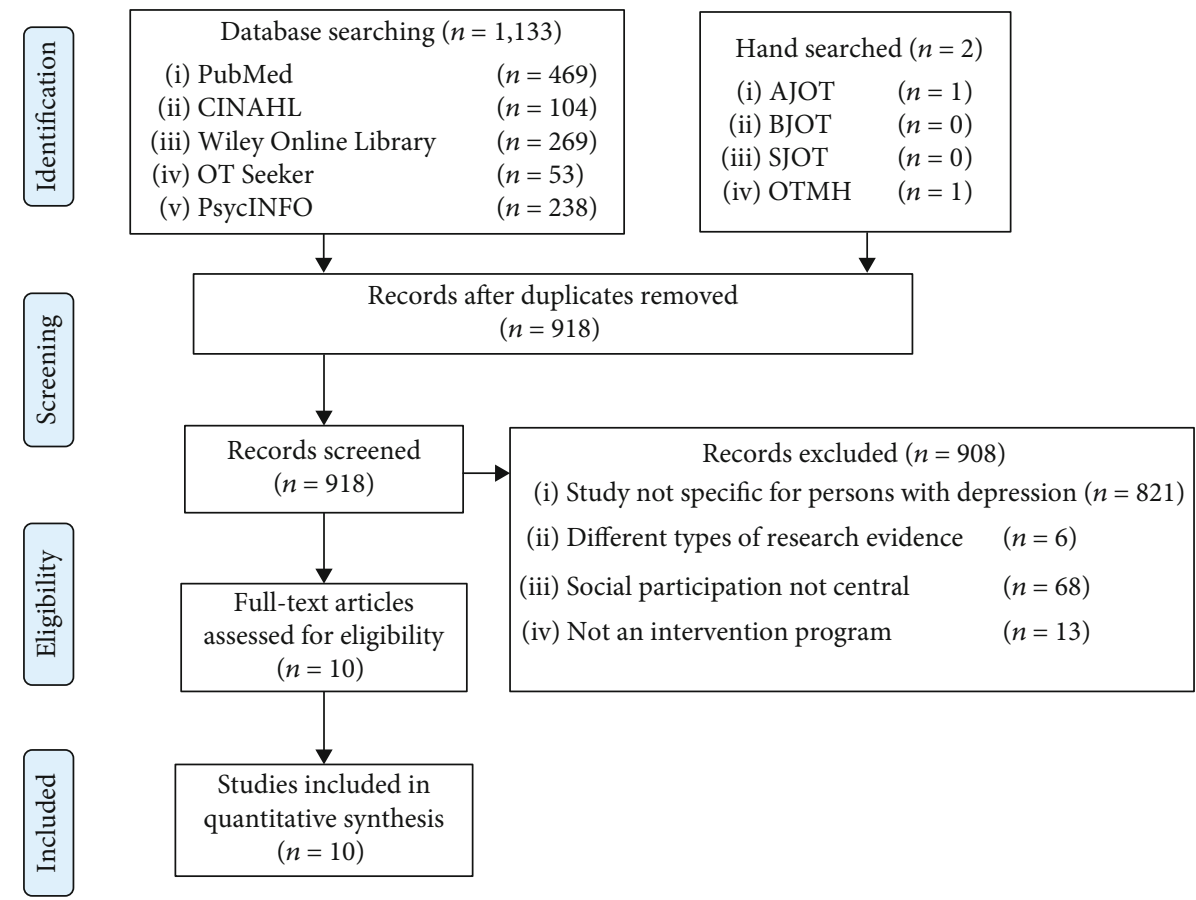

Figure 1: PRISMA flow diagram.

coping. Furthermore, the participants' self-reports indicated a pleasurable and uplifting experience in interpersonal communication, which referred to reduced fear of new situations or interaction with other people and promoting an atmosphere of social participation combined with animals as the therapeutic environment. Second, SEP (Rogers et al. 2014 [35]) correlated avoidance with reduced active behavior but supported motivation searching for lively activity. Participating in many sessions of SEP fulfilled the transformative experience. If such programs could create resilience, it truly helped reflect preferred responsiveness to past preferences and experience. Besides, it reinforced the motivation and acceptance of social participation and encouraged social connection through peer relationships, with focus group processing and collaboration among the participants. Surfing was the only sporting reference [35], and no other type of exercise was suggested in the findings of this review.

Third, BCPHE (Chen et al. 2019 [32]) showed progressive physical function from one to three months after participation. Consecutive sessions from the introduction, 


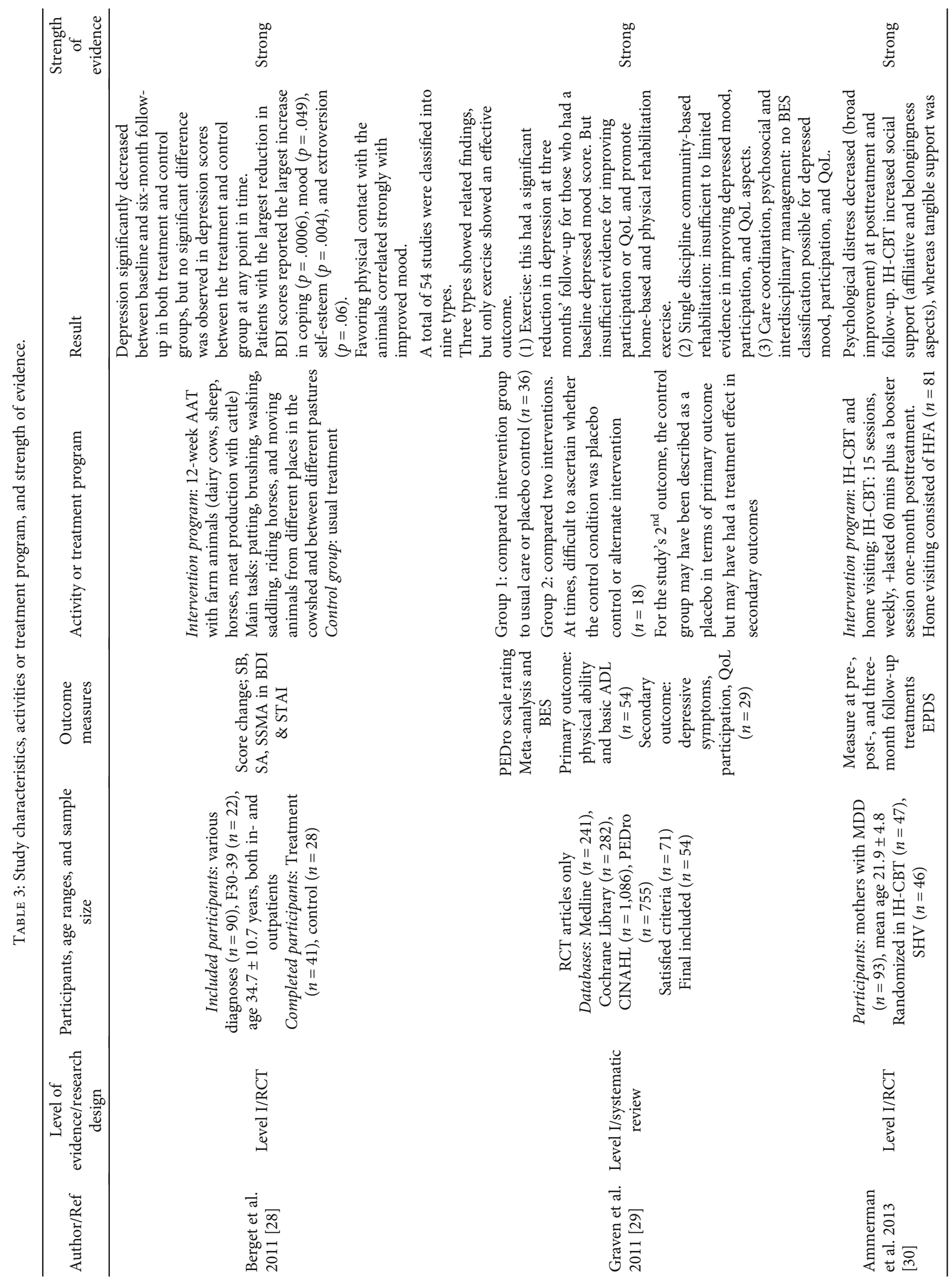




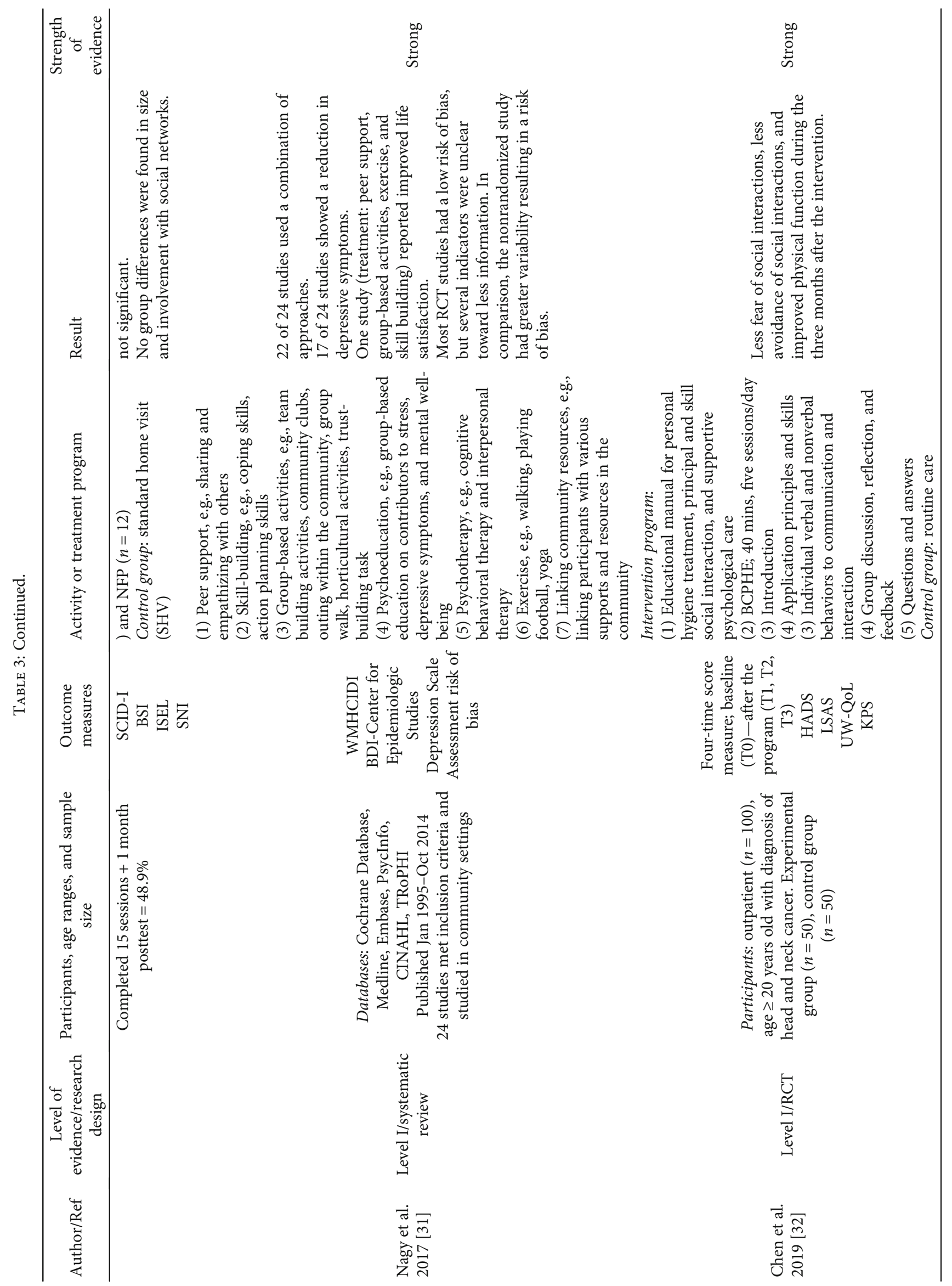




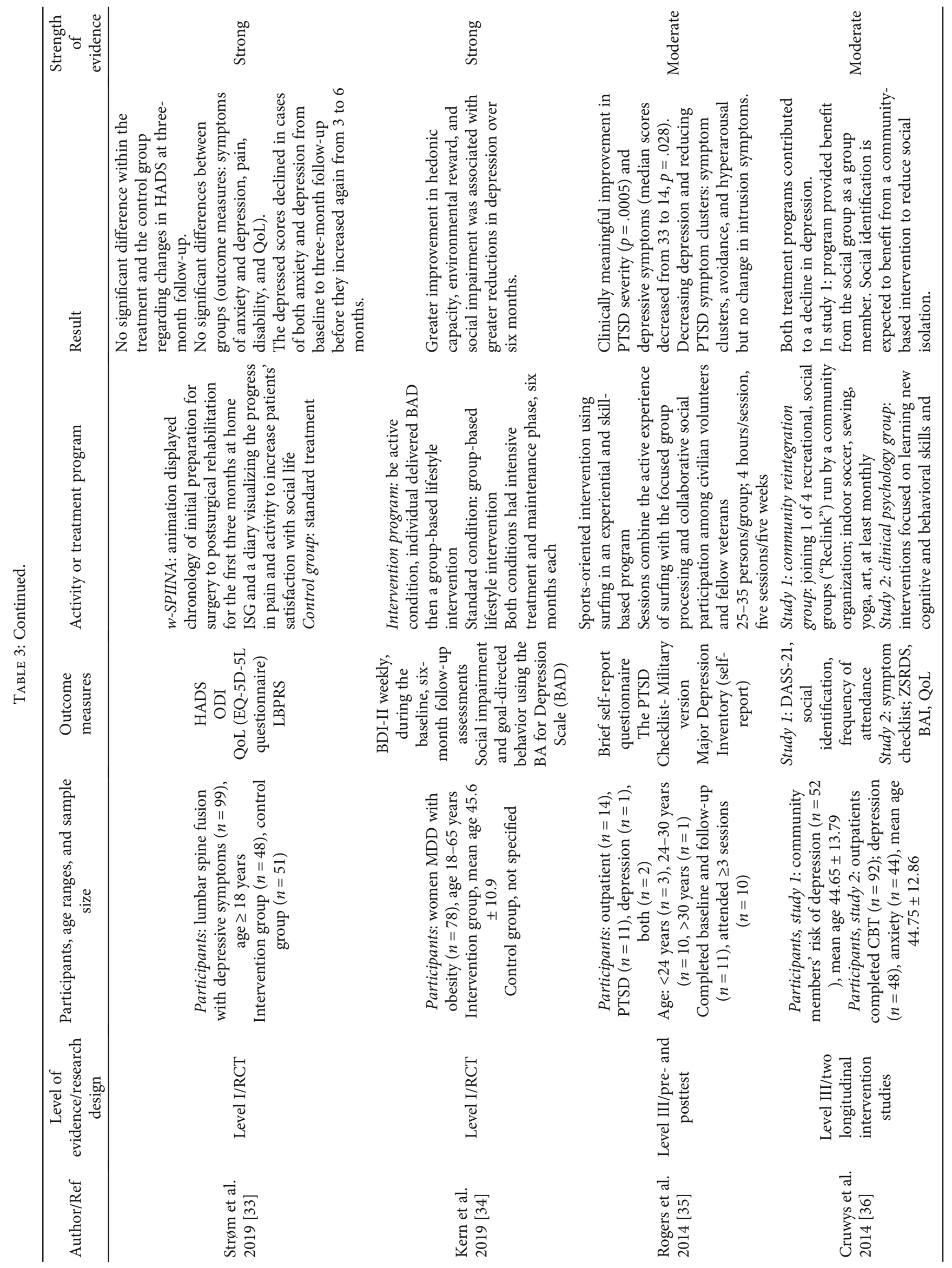




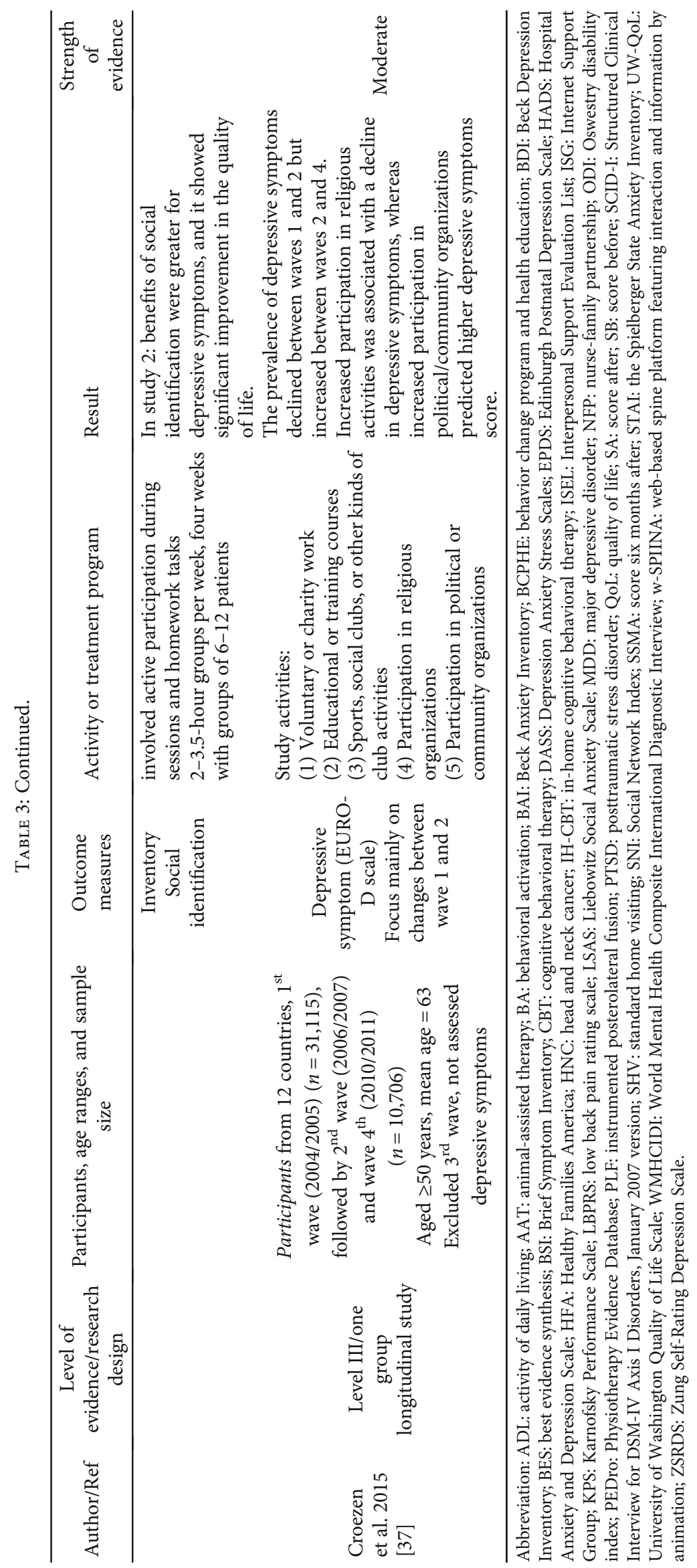


TABle 4: Two major categories of intervention.

\begin{tabular}{|c|c|}
\hline Programs & Authors \\
\hline \multicolumn{2}{|c|}{ Occupational-based intervention (OBI) } \\
\hline $\begin{array}{l}\text { Animal-assisted therapy } \\
\text { (AAT) }\end{array}$ & Berget et al. 2011 [28] \\
\hline $\begin{array}{l}\text { Sport or exercise program } \\
\text { (SEP) }\end{array}$ & $\begin{array}{c}\text { Graven et al. } 2011 \text { [29], Nagy } \\
\text { et al. } 2017 \text { [31], Rogers et al. } \\
2014 \text { [35] }\end{array}$ \\
\hline Religious activity (RA) & Croezen et al. 2015 [37] \\
\hline Group-based activity (GBA) & $\begin{array}{l}\text { Nagy et al. } 2017 \text { [31], Cruwys } \\
\text { et al. } 2014 \text { [36] }\end{array}$ \\
\hline Skill-building program (SBP) & Nagy et al. 2017 [31] \\
\hline $\begin{array}{l}\text { Other social and community } \\
\text { supportive program (OSCSP), } \\
\text { which covers peer support (PS) } \\
\text { and linking community } \\
\text { resource (LCR) }\end{array}$ & Nagy et al. 2017 [31] \\
\hline \multicolumn{2}{|c|}{ Cognitive behavioral therapy-based intervention (CBT-BI) } \\
\hline Web-based program (WBP) & Strøm et al. 2019 [33] \\
\hline $\begin{array}{l}\text { Clinical psychotherapy group } \\
\text { (CPG) }\end{array}$ & Cruwys et al. 2014 [36] \\
\hline $\begin{array}{l}\text { Behavioral change program } \\
\text { and health education (BCPHE) }\end{array}$ & Chen et al. 2019 [32] \\
\hline $\begin{array}{l}\text { In-home cognitive behavioral } \\
\text { therapy and home visit (IH- } \\
\text { CBT+HV) }\end{array}$ & Ammerman et al. 2013 [30] \\
\hline $\begin{array}{l}\text { Behavioral activation for } \\
\text { depression and lifestyle } \\
\text { intervention (BADLI) }\end{array}$ & Kern et al. 2019 [34] \\
\hline Psychoeducation (PsyE) & Nagy et al. 2017 [31] \\
\hline Psychotherapy (PsyT) & Nagy et al. 2017 [31] \\
\hline
\end{tabular}

application of principle into practice, discussion, and reflective feedback from BCPHE may have produced this excellent result [32]. Furthermore, a digital video disc was provided for practicing after the lesson to maintain positive behaviors [32]. Fourth, RA (Croezen et al. 2015 [37]) highlighted growing social participation in the long run by fostering participation after a grandchild's birth or the illness or death of a loved one, such as a child or sibling [37]. RA was arguably at the highest level of social participation than voluntary or charity work, sports and social clubs, educational or training courses, and political or community activities [37].

3.4.2. Depression or Depressive Symptoms. All programs of OBI and CBT-BI presented a reduction of depressive symptoms. Furthermore, SEP (Graven et al. 2011 [29], Nagy et al. 2017 [31], Rogers et al. 2014 [35]), AAT (Berget et al. 2011 [28]), and GBA (Cruwys et al. 2014 [36]) recorded a significant reduction in depression and its symptoms. WBP (Strøm et al. 2019 [33]) and RA (Croezen et al. 2015 [37]) presented a nonsignificant decrease in symptoms during the first follow-up but increased again on subsequent follow-ups at three to six months (Strøm et al. 2019 [33]) or four to five years (Croezen et al. 2015 [37]).
3.4.3. Life Satisfaction. Four programs, SBP, SEP, PS, and GBA from Nagy et al. 2017 [31], showed higher levels of life satisfaction with the social intervention. However, the result was not statistically significant. Life satisfaction in this program covered broader boundaries in receiving a social network, excluding spouse or partner and family relationships.

3.4.4. Quality of Life. SEP (Graven et al. 2011 [29]), WBP (Strøm et al. 2019 [33]), BCPHE (Chen et al. 2019 [32]), and CPG (Cruwys et al. 2014 [36]) studied covering QoL. Each study had different tools to study outcome measurement of QoL. There was QoL (EQ-5D-5L questionnaire) (Strøm et al. 2019 [33]), University of Washington Quality of Life Scale (UW-QoL) (Chen et al. 2019 [32]), and QoL Inventory by Frisch et al. (1992 cited in Cruwys et al. 2014 [36]), while two scales of health-related quality of life (HRQoL) (Stroke Impact Scale-16 item and Short Form-36) were used in two studies of the systematic review (Graven et al. 2011 [29]) along with utilizing best-evidence synthesis (BES) by van Tulder et al. (1999 cited in Graven et al. 2011 [29]). However, only the CPG (Cruwys et al. 2014 [36]) revealed significant improvement in QoL, which is related to decreased depressive symptoms. The BCPHE (Chen et al. 2019 [32]) attempted to measure QoL and its association with physical functioning. Even though the score changed slightly over time in the study, physical limitations still affected the participants' ability to communicate and express social function and QoL. The other programs had insufficient information supporting QoL.

3.4.5. Strength of Evidence. A strong level of certainty was found in seven studies (Berget et al. 2011 [28], Graven et al. 2011 [29], Ammerman et al. 2013 [30], Nagy et al. 2017 [31], Chen et al. 2019 [32], Strøm et al. 2019 [33], Kern et al. 2019 [34]) because they were well-designed and wellconducted at level I of RCT and systematic review studies, possessing a strong finding that met their research objectives. A moderate level of certainty was found in the three other studies (Rogers et al. 2014 [35], Cruwys et al. 2014 [36], Croezen et al. 2015 [37]), as they were at level III of research evidence and had a small sample size or needed future research for more clarification on the effectiveness of the treatment programs. All summaries are illustrated in Table 3.

3.4.6. Risk of Bias. The risk of bias was rated for studies individually (Tables 5 and 6). Among eight studies of nonsystematic reviews, five had different risk of bias items used in the assessment. Low risk of selection bias pointed to five studies (Berget et al. 2011 [28], Ammerman et al. 2013 [30], Chen et al. 2019 [32], Strøm et al. 2019 [33], Kern et al. 2019 [34]), while a high risk of selection bias appeared in the three other studies (Rogers et al. 2014 [35], Cruwys et al. 2014 [36], Croezen et al. 2015 [37]). There was a low risk of performance bias in three studies (Berget et al. 2011 [28], Ammerman et al. 2013 [30], Chen et al. 2019 [32]), whereas a high or unclear risk of performance bias was referred to in five studies (Strøm et al. 2019 [33], Kern et al. 2019 [34], Rogers et al. 2014 [35], Cruwys et al. 2014 [36], Croezen et al. 2015 [37]). Three studies (Strøm et al. 2019 [33], Rogers et al. 2014 [35], 
TABLE 5: Risk-of-bias table for considering nonsystematic reviews.

\begin{tabular}{|c|c|c|c|c|c|c|c|}
\hline \multirow[b]{2}{*}{ Citation } & \multicolumn{2}{|c|}{ Selection Bias } & \multirow{2}{*}{$\begin{array}{l}\text { Performance } \\
\text { bias } \\
\text { Blinding of } \\
\text { participants and } \\
\text { personnel }\end{array}$} & \multicolumn{2}{|c|}{ Detection bias } & \multirow{2}{*}{$\begin{array}{l}\text { Attrition } \\
\text { bias } \\
\text { Incomplete } \\
\text { outcome } \\
\text { data }\end{array}$} & \multirow{2}{*}{$\begin{array}{l}\text { Reporting } \\
\text { bias } \\
\text { Selective } \\
\text { reporting }\end{array}$} \\
\hline & $\begin{array}{c}\text { Random } \\
\text { sequence } \\
\text { generation }\end{array}$ & $\begin{array}{c}\text { Allocation } \\
\text { concealment }\end{array}$ & & $\begin{array}{l}\text { Blinding of outcome } \\
\text { assessment: self-reported } \\
\text { outcomes }\end{array}$ & $\begin{array}{c}\text { Blinding of outcome } \\
\text { assessment: objective } \\
\text { outcomes }\end{array}$ & & \\
\hline $\begin{array}{l}\text { Berget et al. } \\
2011 \text { [28] }\end{array}$ & + & + & + & $?$ & $?$ & + & + \\
\hline $\begin{array}{l}\text { Ammerman } \\
\text { et al. } 2013 \\
{[30]}\end{array}$ & + & + & + & $?$ & $?$ & + & + \\
\hline $\begin{array}{l}\text { Chen et al. } \\
2019 \text { [32] }\end{array}$ & + & + & + & $?$ & $?$ & + & + \\
\hline $\begin{array}{l}\text { Strøm et al. } \\
2019 \text { [33] }\end{array}$ & + & - & - & - & - & + & + \\
\hline $\begin{array}{l}\text { Kern et al. } \\
2019 \text { [34] }\end{array}$ & + & - & $?$ & $?$ & $?$ & + & + \\
\hline $\begin{array}{l}\text { Rogers et al. } \\
2014 \text { [35] }\end{array}$ & - & - & - & - & - & + & + \\
\hline $\begin{array}{l}\text { Cruwys et al. } \\
2014 \text { [36] }\end{array}$ & - & - & - & - & - & + & + \\
\hline $\begin{array}{l}\text { Croezen } \\
\text { et al. } 2015 \\
{[37]}\end{array}$ & - & - & - & $?$ & $?$ & + & + \\
\hline
\end{tabular}

Categories for risk of bias: +: low risk of bias; ?: unclear risk of bias; -: high risk of bias; NA: not applicable. Risk-of-bias table format followed the guideline from Cochrane Handbook for Systematic Reviews of Interventions by Higgins J.P.T., Altman D.G., and Sterne J.A.C., version 5.1.0 (updated March 2011) [25].

TABLE 6: Risk-of-bias table for considering systematic review (AMSTAR).

\begin{tabular}{lcccccccccccc}
\hline Citation & $(1)$ & $(2)$ & $(3)$ & $(4)$ & $(5)$ & $(6)$ & $(7)$ & $(8)$ & $(9)$ & $(10)$ & $(11)$ \\
\hline Graven et al. 2011 [29] & + & + & + & + & + & + & + & & + & + & + \\
Nagy et al. 2017 [31] & + & + & + & + & + & + & + & & + & + & + \\
\hline
\end{tabular}

Note 1. Categories for risk of bias: +: low risk of bias; ?: unclear risk of bias; -: high risk of bias; NA: not applicable. Risk-of-bias table format followed the Development of AMSTAR by Shea et al. [26] and developing reliability and validity of AMSTAR by Shea et al. [27]. Note 2. (1) "a priori design" included? (2) Duplicate study selection/data extraction? (3) Comprehensive literature search performed? (4) Status of publication as inclusion criteria? (5) List of included/excluded studies provided? (6) Characteristics of included studies are provided? (7) Quality of studies assessed and documented? (8) Quality assessment was used appropriately? (9) Methods used to combine results appropriate? (10) Likelihood of publication bias assessed? (11) Conflict of interest stated?

Cruwys et al. 2014 [36]) had a high risk of detection bias because they could not be blinded for providing purposive treatment, and the five other studies (Berget et al. 2011 [28], Ammerman et al. 2013 [30], Chen et al. 2019 [32], Kern et al. 2019 [34], Croezen et al. 2015 [37]) had an unclear risk of detection bias. Every study reported findings with a low risk of attrition and biased reporting. Finally, two studies of systematic reviews (Graven et al. 2011 [29], Nagy et al. 2017 [31]) had a low risk of bias in all items of assessment.

\section{Discussion}

This review revealed that not every treatment program affects all behavioral changes in social participation, reduces depression or depressive symptoms, improves life satisfaction, and improves QoL. It could not be determined which program was the most effective due to the diversity of participants' programs and characteristics. The programs within the systematic reviews included in this study (SEP (Graven et al. 2011 [29],
Nagy et al. 2017 [31]), OSCSP (Nagy et al. 2017 [31]), SBP (Nagy et al. 2017 [31]), GBA (Nagy et al. 2017 [31]), PsyE (Nagy et al. 2017 [31]), PsyT (Nagy et al. 2017 [31]) revealed a strong level of evidence and low risk of bias. AAT (Berget et al. 2011 [28]), IH-CBT+HV (Ammerman et al. 2013 [30]), and BCPHE (Chen et al. 2019 [32]) show a strong level of strength of evidence and a low risk of bias in some items. AAT (Berget et al. 2011 [28]), however, displayed a convincing behavioral and emotional change as the primary outcome compared with BCPHE (Chen et al. 2019 [32]) and RA (Croezen et al. 2015 [37]). Other programs claim to be useful for at least one element of the outcome. WBP (Strøm et al. 2019 [33]) influenced less effectiveness in diminishing depression. Nevertheless, the virtual program might facilitate social interaction in cases of one who needs appropriate social cues or responsiveness with nonbehaviors, particularly severe physical condition. Thus, this program needs further study to confirm behavioral changes in social participation, especially using a more appropriate assessment tool. 
AAT (Berget et al. 2011 [28]), SEP (Graven et al. 2011 [29], Nagy et al. 2017 [31], Rogers et al. 2014 [35]), RA (Croezen et al. 2015 [37]), GBA (Nagy et al. 2017 [31], Cruwys et al. 2014 [36]), SBP (Nagy et al. 2017 [31]), and OSCSP (Nagy et al. 2017 [31]) are occupation-based interventions that challenged and coached participants by receiving direct and indirect feedback from their activity and participation. AAT (Berget et al. 2011 [28]) may improve confronting and dealing with frustration between pleasant and ambivalent feelings when participating socially [38]. As surfing was mentioned in the effective SEP (Rogers et al. 2014 [35]), general types of exercise, such as walking, football, and yoga (Nagy et al. 2017 [31]) did not show significant effective findings of reviewing. However, several sports or exercises were accepted in the literature as beneficial treatments for people with depression [39-43], such as weightlifting [39], aerobic exercise [40], and walking [39]. Thus, these two programs are highly recommended for improving social participation in adults with depression. The RA enabled social participation, spirituality, and mental health through religious observance as an occupation $[44,45]$. Even though there was no report on the frequency and direction in the mechanism of behavior in the participation, it helped in uplifting mood [37] as active religious persons might protect themselves from depression by receiving social attachment [45] and promoting a coping mechanism [46]. On the other hand, a study argued that participating in religious activity may enhance feelings of guilt or discouragement, depending on tradition [46]. This review concluded that this program, which promoted social participation, is associated with declining depression over a long period of time, even though it was at the moderate level of certainty and had high and unclear risk of bias. Thus, these programs go against depression resulting in participation promoted by creating real supportive physi$\mathrm{cal}$ and social environments. Therefore, they can be useful training programs for improving mental health in independent living [8, 47]. Furthermore, the importance of these treatment programs, from cultivated evidence, should be highlighted more and integrated into occupational therapy practice to promote expressive behavioral change in social participation and encourage self-love, self-worth, and a sense of belonging. Meanwhile, these programs promote mental and social health as stimulation for physical health and well-being.

CPG (Cruwys et al. 2014 [36]), WBP (Strøm et al. 2019 [33]), BCPHE (Chen et al. 2019 [32]), BADLI (Kern et al. 2019 [34]), IH-CBT+HV (Ammerman et al. 2013 [30]), PsyE (Nagy et al. 2017 [31]), and PsyT (Nagy et al. 2017 [31]) were tied basically to the study of psychology and the social learning theory in supportive psychoeducation, CBT, and behavioral activation (BA). They increased the familiarity of the activity and shifted decision-making from being an obstacle-focused to participation-focused [36]. This review could not ignore the benefit of CBT programs in the intervention of social participation, as they integrate suitably into the treatment program for depression, in order to obtain selfefficacy and personal performance, especially in shifting decision-making, which is an obstacle in developing social participation in the initial stage of nonpharmacological treatment.
Thus, these programs help to establish a visible behavioral change in social participation and affirm the programs at the strong level of certainty and low risk of bias, especially in the study of the behavioral change program [32]. Health care practitioners can use these programs to impart social support by matching individual goals with social needs to improve treatment responsiveness and develop social skills [48] that possibly advocate QoL and prevent the risk of depression relapse. The application of treatment in social participation programs occurs in a real environment. Hence, there is a merit in integrating community-based rehabilitation (CBR) and CBT into these programs to improve social participation, life satisfaction, and QoL among adults with depression. OSCSP (Nagy et al. 2017 [31]), SEP (Graven et al. 2011 [29], Nagy et al. 2017 [31]), SBP (Nagy et al. 2017 [31]), GBA (Nagy et al. 2017 [31]), PsyT (Nagy et al. 2017 [31]), and PsyE (Nagy et al. 2017 [31]) were arranged recently in $\mathrm{CBR}$ promotion since having $\mathrm{CBR}$ in promoting social participation treatment programs $[48,49]$ contributes to mental health not only for people with depression but also in creating good social support for their family and community members.

Strong evidence was presented in most programs; however, an essential factor of the considerable rating level of certainty depended on whether their assessment tools were suitable or further study was needed. The assessment risk of bias was low in systematic review studies. The studies were considered as having nonsystematic reviews if they had a high risk of bias, except for some RCT studies. However, some parts of the RCT studies had a high risk of bias regarding advantages for the participants because they could not design the study with blinded personnel in treatment and outcome measurement. This systematic review provides a comprehensive appraisal of the effectiveness of intervention programs that support social participation for adults with depression and advocate the necessity of occupational therapy and healthcare services in the nonpharmacological treatment for depression in both clinical and community settings.

\section{Limitation}

This review gathered and classified the intervention programs to support social participation in adults with depression; however, this study's limitations should also be considered. Accordingly, the researchers focused more on nonpharmacological treatment in support of social participation and evidence in occupational therapy research, and several articles showed limitations after screening. Expanding databases and years of searching relate to a change of results when reviewing. Interpretation of the findings from several intervention programs was carefully performed because of the variation in examining intervention, diagnosis, and age range of the participants. The age of participants was accepted if the articles concerned only adolescents aged 16 years and above [30], 18 years and over [34,35], or adults aged 50 years and more [37]. Thus, this research reviewed the reviewing structure, and the results met the research objective. As a suggestion for further research, participants could be extended to adolescents or older people, which 
may show various activities or treatment programs of social participation. Most of the articles in this study seemed to have unclear confirmation of behavioral change expression in social participation due to the use of self-report assessment tools and limited findings in elucidating life satisfaction and QoL. Thus, future studies can focus on identifying these issues and how they work. When promoting social participation in a group of people with depression, the implications of this study may raise awareness on the matter.

\section{Conclusion}

This study reviewed the evidence of nonpharmacological treatments that illustrate intervention programs and their effect on social participation for adults with depression. Programs were categorized as OBI or CBT-BI and summarized in order to demonstrate the effectiveness of interventions. Four programs (AAT, SEP, RA, and BCPHE) demonstrated visible behavioral changes in social participation. All intervention programs reported decreasing depressive symptoms. Four intervention programs (SBP, SEP, PS, and GBA) illustrated life satisfaction, whereas only CPG promoted QoL. Based on the result of this review, AAT, SEP, and BCPHE are recommended. A combined treatment with a flexible and suitable application for covering higher benefits in promoting social participation, reducing depression, and contributing to life satisfaction and QoL is recommended for other programs.

\section{Data Availability}

The reviewing data used to support the findings of this study are included within the article.

\section{Conflicts of Interest}

The authors declare no conflict of interest regarding the publication of this paper.

\section{Acknowledgments}

The authors would like to acknowledge the Tokyo Human Resources Fund for City Diplomacy for granting scholarship to the primary investigator during her pursuit of a Ph.D. in Occupational Therapy at the Tokyo Metropolitan University.

\section{References}

[1] D. Wan, "Depression: a global crisis. World Mental Health Day, October 10 2012," 2012, https://www.who.int/mental_ health/management/depression/wfmh_paper_depression_ wmhd_2012.pdf?Ua $=1 \% 0 D$.

[2] S. L. Burcusa and W. G. Iacono, "Risk for recurrence in depression," Clinical Psychology Review, vol. 27, no. 8, pp. 959-985, 2007.

[3] E. S. Friedman, "Classification, causes, and epidemiology," in Handbook of Depression, E. S. Friedman and I. M. Anderson, Eds., pp. 1-11, Springer Health Care Ltd., London, 2nd edition, 2014.

[4] K. Gibson, C. Cartwright, and J. Read, "Patient-centered perspectives on antidepressant use," International Journal of Mental Health, vol. 43, no. 1, pp. 81-99, 2014.
[5] American Occupational Therapy Association, "Occupational therapy practice framework: domain and process - Fourth Edition," American Journal of Occupational Therapy, vol. 74, Supplement 2, p. 7412410010, 2020.

[6] S. Tsu and N. W. Spangler, "Mood disorder," in Occupational Therapy in Mental Health: A Vision for Participation, C. Brown, V. C. Stoffel, and J. P. Munoz, Eds., pp. 182-192, F.A. Davis Company, Philadelphia, 2nd ed. edition, 2019.

[7] World Health Organization, "International Classification of Functioning, Disability and Health," Geneva, 2001https://apps .who.int/iris/bitstream/handle/10665/42407/9241545429.pdf.

[8] C. Lloyd and F. P. Deane, "Social participation," in Occupational Therapy in Mental Health: A Vision for Participation, C. Brown, V. C. Stoffel, and J. P. Munoz, Eds., pp. 881-891, F.A. Davis Company, Philadelphia, 2nd edition, 2019.

[9] G. Gartlehner, G. Wagner, N. Matyas et al., "Pharmacological and non-pharmacological treatments for major depressive disorder: review of systematic reviews," British Medical Journal Open (BMJ Open), vol. 7, no. 6, p. e014912, 2017.

[10] I. M. Anderson and D. Arnone, "Medications," in Handbook of Depression, E. S. Friedman and I. M. Anderson, Eds., pp. 5167, Springer Healthcare Ltd., London, 2nd edition, 2014.

[11] S. C. Ho, S. A. Jacob, and B. Tangiisuran, "Barriers and facilitators of adherence to antidepressants among outpatients with major depressive disorder: a qualitative study," PLoS One, vol. 12, no. 6, article e0179290, 2017.

[12] S. R. Koujalgi and S. R. Patil, "Family burden in patient with schizophrenia and depressive disorder: a comparative study," Indian Journal of Psychological Medicine, vol. 35, no. 3, pp. 251-255, 2013.

[13] K. Evans, H. Spiby, and J. C. Morrell, "Non-pharmacological interventions to reduce the symptoms of mild to moderate anxiety in pregnant women. A systematic review and narrative synthesis of women's views on the acceptability of and satisfaction with interventions," Archives of Women's Mental Health, vol. 23, no. 1, pp. 11-28, 2020.

[14] J. Apóstolo, E. Bobrowicz-Campos, M. Rodrigues, I. Castro, and D. Cardoso, "The effectiveness of non-pharmacological interventions in older adults with depressive disorders: a systematic review," International Journal of Nursing Studies, vol. 58, pp. 59-70, 2016.

[15] R. Ma, F. Mann, J. Wang et al., "The effectiveness of interventions for reducing subjective and objective social isolation among people with mental health problems: a systematic review," Social Psychiatry and Psychiatric Epidemiology, vol. 55, no. 7, pp. 839-876, 2020.

[16] S. Smallfield and W. L. Molitor, "Occupational therapy interventions supporting social participation and leisure engagement for community-dwelling older adults: a systematic review," American Journal of Occupational Therapy, vol. 72, no. $4,2018$.

[17] J. A. Nastasi, “Occupational therapy interventions supporting leisure and social participation for older adults with low vision: a systematic review," American Journal of Occupational Therapy, vol. 74, no. 1, pp. 7401185020p1-7401185020p9, 2020.

[18] M. Webber and M. Fendt-Newlin, "A review of social participation interventions for people with mental health problems," Social Psychiatry and Psychiatric Epidemiology, vol. 52, no. 4, pp. 369-380, 2017.

[19] D. Moher, L. Shamseer, M. Clarke et al., "Preferred reporting items for systematic review and meta-analysis protocols 
(PRISMA-P) 2015 statement," Systematic Reviews, vol. 4, no. 1, pp. 1-9, 2015.

[20] D. L. Sackett, W. M. Rosenberg, J. A. M. Gray, R. B. Haynes, and W. S. Richardson, "Evidence based medicine: what it is and what it isn't," British Medical Journal (BMJ), vol. 312, pp. 71-72, 1996.

[21] D. L. Sackett, "Rules of evidence and clinical recommendations on the use of antithrombotic agents," Chest, vol. 95, 2 Supplement, pp. 2S-4S, 1989.

[22] O. O. Daramola and J. S. Rhee, "Rating evidence in medical literature," Virtual Mentor, vol. 13, no. 1, pp. 46-51, 2011.

[23] L. E. Bothwell, J. A. Greene, S. H. Podolsky, and D. S. Jones, "Assessing the gold standard - lessons from the history of RCTs," The New England Journal of Medicine, vol. 374, no. 22, pp. 2175-2181, 2016.

[24] U.S. Preventive Services Task Force, "The strength of the evidence is based on the guidelines of the U.S. Preventive Services Task Force," 2018, https://www.uspreventiveservicestaskforce .org/Page/Name/grade-definitions.

[25] J. P. T. Higgins, D. G. Altman, and J. A. C. Sterne, "Chapter 8: assessing risk of bias in included studies," Cochrane Handbook for Systematic Reviews of Interventions Version 5.1.0 (updated March 2011), J. P. T. Higgins and S. Green, Eds., 2011, https://handbook-5-1.cochrane.org/front_page.htm.

[26] B. J. Shea, J. M. Grimshaw, G. A. Wells et al., "Development of AMSTAR: a measurement tool to assess the methodological quality of systematic reviews," BMC Medical Research Methodology, vol. 7, no. 1, pp. 1-7, 2007.

[27] B. J. Shea, C. Hamel, G. A. Wells et al., "AMSTAR is a reliable and valid measurement tool to assess the methodological quality of systematic reviews," Journal of Clinical Epidemiology, vol. 62, no. 10, pp. 1013-1020, 2009.

[28] B. Berget, Ø. Ekeberg, I. Pedersen, and B. O. Braastad, “Animal-assisted therapy with farm animals for persons with psychiatric disorders: effects on anxiety and depression, a randomized controlled trial," Occupational Therapy in Mental Health, vol. 27, no. 1, pp. 50-64, 2011.

[29] C. Graven, K. Brock, K. Hill, and L. Joubert, "Are rehabilitation and/or care co-ordination interventions delivered in the community effective in reducing depression, facilitating participation and improving quality of life after stroke?," Disability and Rehabilitation, vol. 33, no. 17-18, pp. 1501-1520, 2011.

[30] R. T. Ammerman, F. W. Putnam, M. Altaye, A. R. Teeters, J. Stevens, and J. B. Van Ginkel, "Treatment of depressed mothers in home visiting: impact on psychological distress and social functioning," Child Abuse \& Neglect, vol. 37, no. 8, pp. 544-554, 2013.

[31] E. Nagy and S. Moore, "Social interventions: an effective approach to reduce adult depression?," Journal of Affective Disorders, vol. 218, pp. 131-152, 2017.

[32] S. C. Chen, B. S. Huang, T. M. Hung, C. Y. Lin, and Y. L. Chang, "Impact of a behavior change program and health education on social interactions in survivors of head and neck cancer: randomized controlled trial," Psycho-Oncology, vol. 28, no. 2, pp. 293-300, 2019.

[33] J. Strøm, C. V. Nielsen, L. B. Jørgensen, N. T. Andersen, and M. Laursen, "A web-based platform to accommodate symptoms of anxiety and depression by featuring social interaction and animated information in patients undergoing lumbar spine fusion: a randomized clinical trial," The Spine Journal, vol. 19, no. 5, pp. 827-839, 2019.
[34] D. Kern, A. Busch, K. L. Schneider et al., "Psychosocial factors associated with treatment outcomes in women with obesity and major depressive disorder who received behavioral activation for depression," Journal of Behavioral Medicine, vol. 42, no. 3, pp. 522-533, 2019.

[35] C. M. Rogers, T. Mallinson, and D. Peppers, "High-intensity sports for posttraumatic stress disorder and depression: feasibility study of ocean therapy with veterans of operation enduring freedom and operation Iraqi freedom," American Journal of Occupational Therapy, vol. 68, no. 4, pp. 395-404, 2014.

[36] T. Cruwys, S. Alexander Haslam, G. A. Dingle et al., "Feeling connected again: interventions that increase social identification reduce depression symptoms in community and clinical settings," Journal of Affective Disorders, vol. 159, pp. 139146, 2014.

[37] S. Croezen, M. Avendano, A. Burdorf, and F. J. Van Lenthe, "Social participation and depression in old age: a fixed-effects analysis in 10 European countries," American Journal of Epidemiology, vol. 182, no. 2, pp. 168-176, 2015.

[38] S. Salo-Chydenius, "Application of occupational therapy in the treatment of depression," Occupational Therapy International, vol. 1, no. 2, 121 pages, 1994.

[39] A. M. Busch, J. T. Ciccolo, A. J. Puspitasari, S. Nosrat, J. W. Whitworth, and M. A. Stults-Kolehmainen, "Preferences for exercise as a treatment for depression," Mental Health and Physical Activity, vol. 10, pp. 68-72, 2016.

[40] I. D. Morres, A. Hatzigeorgiadis, A. Stathi et al., "Aerobic exercise for adult patients with major depressive disorder in mental health services: a systematic review and meta-analysis," Depression and Anxiety, vol. 36, no. 1, pp. 39-53, 2019.

[41] A. Ströhle, "Physical activity, exercise, depression and anxiety disorders," Journal of Neural Transmission, vol. 116, no. 6, pp. 777-784, 2009.

[42] L. L. Craft and F. M. Perna, "The benefits of exercise for the clinically depressed," Primary Care Companion to The Journal of Clinical Psychiatry, vol. 6, no. 3, pp. 104-111, 2004.

[43] P. J. Carek, S. E. Laibstain, and S. M. Carek, "Exercise for the treatment of depression and anxiety," The International Journal of Psychiatry in Medicine, vol. 41, no. 1, pp. 15-28, 2011.

[44] D. B. McCraith, "Cognitive beliefs," in Occupational Therapy in Mental Health: A Vision for Participation, C. Brown, V. C. Stoffel, and J. P. Munoz, Eds., pp. 301-318, F.A. Davis Company, Philadelphia, 2nd edition, 2019.

[45] D. Vink, M. J. Aartsen, and R. A. Schoevers, "Risk factors for anxiety and depression in the elderly: a review," Journal of Affective Disorders, vol. 106, no. 1-2, pp. 29-44, 2008.

[46] R. Bonelli, R. E. Dew, H. G. Koenig, D. H. Rosmarin, and S. Vasegh, "Religious and spiritual factors in depression: review and integration of the research," Depression Research and Treatment, vol. 2012, 8 pages, 2012.

[47] S. Vasegh, D. H. Rosmarin, H. G. Koenig, R. E. Dew, and R. M. Bonelli, "Religious and spiritual factors in depression," Depression Research and Treatment, vol. 2012, 3 pages, 2012.

[48] K. Haertl, "Coping and resilience," in Occupational Therapy in Mental Health: A Vision for Participation, C. Brown, V. C. Stoffel, and J. P. Munoz, Eds., pp. 342-365, F.A. Davis Company, Philadelphia, 2nd edition, 2019.

[49] P. Cuijpers, A. van Straten, and L. Warmerdam, "Are individual and group treatments equally effective in the treatment of depression in adults? A meta-analysis," The European Journal of Psychiatry, vol. 22, no. 1, pp. 38-51, 2008. 